\title{
Ergenlerde Ebeveyn Akademik Başarı Baskısı ve Desteği ile Sınav Kaygısı Arasındaki İlişkide Akademik Dayanıklıığın Aracı Rolü*
}

\section{The Mediator Role of Academic Resilience in the Relationship between Parental Academic Success Pressure and Support and Test Anxiety in Adolescents}

Şahin KAPIKIRAN**

• Geliş Tarihi: 02.02.2019 • Kabul Tarihi: 23.07.2019 • Çevrimiçi Yayın Tarihi: 23.07.2019

$\ddot{O} \mathbf{z}$

Bu çalışmanın amacı, ergenlerde, ebeveyn akademik başarı baskısı ve desteği ile sınav kaygısı arasındaki ilişkide akademik dayanıklılığın doğrudan ve dolaylı rolünü incelemektir. Çalışma, 9 ile 12. sınıf lise öğrencilerini içermektedir. Öğrencilerin 223'ü k1z, 167'si erkek olmak üzere toplam 390 kişiden oluşmaktadır. Araştırmada, öğrencilere ebeveyn akademik başarı baskısı - desteği, sınav kaygısı ve akademik dayanıklılık ölçekleri uygulanmıştır. Araştırmanın amacına uygun olarak aracılık analizi yapısal eşitlik modeline dayalı olarak yapılmıştır. Analiz sonucunda, önerilen modele ait uyum değerlerinin yeterli düzeyde olduğu bulunmuştur. Akademik dayanıklılığın ebeveyn akademik başarı desteği ve sınav kaygısı arasında tam aracılığı olduğu $(\beta=-13, \mathrm{P}<.05-\beta=-.03, \mathrm{P}>.05)$ saptanmıştır. Akademik dayanıklılığın, ebeveyn akademik başarı baskısı ile sınav kaygısı arasında kısmi aracılık rolü olduğu $(\beta=.21, \mathrm{P}<.01-\beta=.17, \mathrm{P}<.01)$ bulunmuştur. Ayrıca ebeveyn başarı baskısı ile sınav kaygısı arasında olumlu, akademik dayanıklılık ile olumsuz yönde ilişkili olurken, ebeveyn başarı desteği ile sınav kaygısı arasında olumsuz ve akademik dayanıklılık ile olumlu yönde ilişkili olduğu bulunmuştur. $\mathrm{Bu}$ sonuçlar, sınav kaygısı, ebeveyn akademik başarı baskısı, ebeveyn akademik başarı desteği ve akademik dayanıklılık bağlamında tartışılmıştır.

Anahtar sözcükler: ebeveyn başarı baskısı- desteği, sınav kaygısı, akademik dayanıklılık

Atıf:

Kapıkıran, Ş. (2020). Ergenlerde ebeveyn akademik başarı baskısı ve desteği ile sınav kaygısı arasındaki ilişkide akademik dayanıklılığın aracılık rolü. Pamukkale Üniversitesi Eğitim Fakültesi Dergisi, 48, 409-430. doi:10.9779/pauefd.521230

\footnotetext{
* Bu çalışmanın bir kısmı, Pamukkale Üniversitesi Bilimsel Araştırma Projeleri Koordinatörlüğü tarafından 2018KKP297 no'lu kongre desteği kapsamında desteklenmiş olup 2018 y1lında The 4th International Congress on Education Sciences and Learning Technology (ICESLT)'de sözlü bildiri olarak sunulmuştur.

** Prof.Dr., Pamukkale Üniversitesi Eğitim Fakültesi Psikolojik Danışma ve Rehberlik AD, ORCID: 0000-00029693-7660, skkiran@pau.edu.tr
} 


\begin{abstract}
The aim of this study was to investigate the direct and indirect role of academic resilience in the relationship between parental academic achievement pressure and support and test anxiety in adolescents. The study included 9th and 12th grade high school students. Parental academic achievement pressure support, exam anxiety and academic resilience scales were applied in the study. For the purpose of the study, the mediation analysis was based on the structural equation model. As a result of the analysis, it was found that the compliance values of the proposed model were enough. It was found that academic resilience was the complete mediation between parental academic success support and test anxiety $(\beta=-$ $13, \mathrm{P}<.05-\beta=-.03, \mathrm{P}>.05)$. Academic resilience was found to be a partial mediator between parental academic achievement pressure and test anxiety $(\beta=.21, \mathrm{P}<.01-\beta=.17, \mathrm{P}<.01)$. In addition, there was a positive correlation between parent achievement pressure and test anxiety, and a negative correlation with academic resilience. These results were discussed in the context of test anxiety, parental academic success pressure, parental academic achievement support and academic resilience.
\end{abstract}

Keywords: parent academic achievement pressure-support, test anxiety, academic resilience

\title{
Cited:
}

Kapıkıran, Ş. (2020). The mediator role of academic resilience in the relationship between parental academic succes pressure and support and test anxiety in adolescents. Pamukkale Üniversitesi Ĕ̈itim Fakültesi Dergisi, 48, 409-430. doi:10.9779/pauefd.521230 


\section{Giriş}

Türkiye'de öğrencilerin en zorlu okul dönemlerinden birisi lisedir. Çoğu lise öğrencisi yükseköğrenime devam etmek veya istediği bir bölüm için zorlu bir sınava hazırlanmak zorundadır. Ancak öğrencilerin çok az kısmı istediği bir bölüme kayıt yapabilmektedir. Çoğu öğrenci herhangi bir örgün eğitim kurumuna kayıt dahi yapamamaktadır. Üniversite sınavlarına giren 2 milyon 365 bin öğrencinin yaklaşık \%20 sinin (422.946) 4 yıllık bir örgün eğitim veren üniversiteye (Devlet ve özel üniversiteler) yerleşmektedir (ÖSYM, 2017, s.1-2). Üstelik bu öğrencilerin çoğu yerleştikleri okullardan mezun olduklarında, alanlarına uygun bir iş bulma olasılıkları da düşüktür. İşsizlik verilerine göre, üniversite mezunu genç işsizler oranı geçen yıldan bugune artı̧̧ göstermektedir (TUIK, Mart 2017). Dolayısıyla gelecekte istenilen düzeyde iş sağlayacak bir üniversite veya bölüm için talep yüksek ancak girişi zordur. Prestijli bir üniversite ve bölümlere girebilmek için öğrenciler arasında çok sıkı bir rekabet mevcuttur. Anne-babalar, çocuklarının kendi beklentilerine uygun bir başarıya ulaşmaları için daha fazla çalışmaları gerektiği düşüncesi ile çocuklarına baskı yapabilmektedirler (Kapıkıran, 2016). Bu baskılar çoğu zaman sınav kaygısına neden olabilmektedir.

\section{Sinav Kaygisı}

Sınav kaygısı, sınavlarda ya da diğer formal değerlendirme becerilerinde zayıf performansa yol açan korku olarak tanımlanır (Beidel, Turner ve Trager, 1994, s. 170). Bir sınav öncesi ve sınav sürecinde kişi performansını değerlendiremiyorsa, sınanmak için kendini hazır hissetmiyorsa, yeteneğinden emin değilse ya da en iyi olma konusunda performansının düşük olduğunu düşünüyorsa ve kendisini gergin, endişeli, üzüntülü hissediyorsa kişinin sınav kaygısı var demektir (McDonald, 2001, s. 90). Yapılan birçok çalışmada, sınav kaygısının bireyin sınav performansını düşürdügü kaydedilmiş̧ir (Besharat 2003, s. 1052; Cassady ve Johnson, 2002, s. 284; Chapell, vd., 2005, s.271; Xiao, 2013, s. 63). Günümüz yoğun rekabet ortamında bir kısım öğrenci sınav kaygısı yaşamaktadır. Yapılan bir çalışmada, üniversite giriş sınavlarına giren öğrencilerin yaklaşı \%39'unda sınav kaygısının olduğu kaydedilmiştir (Şahin, Günay ve Batı, 2006, s.111). Sınav kaygısının birçok nedeni olabilir. Örneğin, anneleri tarafından sıkı denetim algısına sahip olan lise öğrencilerinin sınav kaygısı yüksek olarak bulunmuştur (Güler ve Çakır, 2013, s. 8). Sınav kaygısı, düşük akademik sonuçların başlıca sebebini oluşturmasının yanı sıra (Balogun, Balogun ve Onyencho, 2017), duygusal olarak başa çıkmada güçlük çekme (Thomas, Cassady ve Heller, 2017, s. 44), stres, sosyal ilişki kurmakta güçlük (Hoferichter, Raufelder ve Eid, 2014, s. 740) gibi duygusal ve sosyal sorunların da yaşanmasına neden olabilmektedir.

\section{Ebeveyn akademik başarı baskısı ve desteği}

Ebeveynler, okul giriş sınavlarına hazırlanan çocuklarının başarılarını artırmak için, destek kadar bask1 da yapabilmektedirler. Bronstein, Ginsburg ve Herrera (2005, s. 570) 7. sinıf öğrencileri ile yaptığı bir boylamsal çalışmada, ebeveynlerin çocuklarının başarı güdülerini artırmak için "dışsal kontrol, ısrarcı ve sürekli hatırlatma yapma" biçiminde davranışlarda bulunduklarını saptamışlardır. Ayrıca, ebeveyn akademik başarı baskısı, anne babaların çocuklarından gerçekçi olmayan başarı beklentisi nedeniyle aşırı çalışma isteğinde bulunması, başka çocuklarla kıyaslaması ve başarılarını küçümsemesi gibi olumsuz davranışları ile de kendini gösterebilir. Bu tür tutumlar çocuklarda baskı olarak algılanabilmektedir. Başka bir deyişle, ebeveyn akademik başarı baskısı ebeveynlerin çocuklarını kendi başarı standartlarına ulaşmaya zorlamasıdır. Ebeveynlerin başarı baskısı çocuklarının yalnızca başarılarını etkilemez, 
çocukların duygusal ve sosyal gelişimlerini de etkileyebilir (Kapıkıran, 2016). Örneğin, algılanan ebeveyn başarı baskısı çocukların kişisel sıkıntılarını artırabilirken (Luthar ve Becker, 2002, s. 1600) benlik saygısını düşürebilmektedir (Adams, Ryan, Ketsetzis ve Keating, 2000, s. 240; Ketsetzis, Ryan ve Adams, 1998, s. 379). Çocuklar ebeveynlerin beklentilerini karşılama istekleri doğrultusunda baskı hissedebilirler. Ebeveynlerini hayal kırıklığına uğratmamak için, iyi performans göstermesi yönünde endişelenirler. Bazı ebeveynler ise, çocuklarını bir sınava hazırlamak ya da bu sınava girmeye teşvik etmek için sosyo-akademik destek sunarlar (Ringeisen ve Raufelder, 2015, s.68). Ebeveynler çocuklarına öğrenme materyalleri sunma, bilgi desteği sağlama ve öğrenmelerini kolaylaştırmaya (Özel ders gibi) yönelik davranışsal destek sağlayabilirler (Raufelder, Hoferichter, Ringeisen, Regner ve Jacke, 2015, s. 3743). Ebeveynler istenilen düzeyde başarı sağlayamayacaklarına inandıkları bir süreçte, çocukların duygusal sıkıntılarını anlamak, onlarla baş etmesi yönünde onlara güven telkin etmek gibi duygusal destek sunduklarında, çocukların okul performansını olumlu yönde etkileyebilir. Diğer bir deyişle, anne-babalar çocuklarının akademik yeteneklerine güveniyorlarsa, onları bağımsız ve sevecen bir şekilde yetiştiriyorlarsa, akademik yetenek ve çabalarına vurgu yaptıktan sonra övüyorlarsa (Ginsburg ve Bronstein, 1993, s. 1467), okullariyla daha ilgililerse (GonzalezDeHass, Willems ve Holbein, 2005, s.108), başarılarını ödüllendiriyorlarsa, çalışmalarına katkıda bulunmak için yardım ediyor ve bilişsel olarak uyarıcı bir ev ortamı sağlıyorlarsa (Gottfried, Fleming, ve Gottfried, 1994, s. 110) çocuklarının akademik başarı ve içsel güdülerinin yüksek, sınıf performanslarının daha iyi olduğu bulunmuştur. Ayrıca, yüksek ebeveyn desteğine sahip öğrencilerin okul uyumları (Wang ve Eccles 2012, s. 884) ve akademik başarılarının daha yüksek olduğu bulunmuştur (Chen, 2005, s. 100; Ringeisen ve Raufelder, 2015, s.72). Bunlara ek olarak ebeveyn desteği, çocukların okul başarısıyla ilgili olarak ortaya çıkabilecek güçlükler karşısında daha güçlü olmalarını da sağlamaktadır (Núñez vd., 2015). Aksine, çocuklarından gerçekçi olmayan bir beklentiye sahip ebeveynlerin çocukları, bu beklentiyi başarılı olma baskısı olarak algılayabilirler. Bu baskı karşısında, çocuklar başarmaları gereken görevlerde çeşitli güçlükler yaşayabilirler (Quach, Epstein, Riley, Falconier ve Fang, 2015). Bununla beraber, bazı öğrenciler karşılaştıkları tüm güçlüklere rağmen akademik olarak dayanıklı olabilirler.

\section{Akademik dayanıklılık}

Öğrencilerin akademik başarı elde etmeleri için yalnızca potansiyellerinin ve enerjilerinin olması yeterli değildir. Aynı zamanda öğrencilerin okulda karşılaştığı stres, çalışma baskısı ve akademik sıkıntılarla da etkili biçimde başa çıkabilmeleri için donanımlarının da buna uygun olması gerekir (Martin, 2002, s. 35). Akademik başarı için öğrencilerin sahip olması gereken psiko-sosyal donanımlardan birisi akademik dayanıklılıktır. Akademik dayanıklılık, eğitimsel süreçte sebatlı, olumlu ve uyumlu olma yeteneği olarak tanımlanmıştır (Perrone, Sedlacek ve Alexander, 2001, s. 170). Başka bir tanıma göre, akademik dayanıklılık öğrencilerin eğitimsel süreçte karşılaştıkları önemli tehditler, kronik ve/veya akut sıkıntılara karşı koyabilme kapasitesidir (Martin, 2013, s. 489). Akademik olarak dayanıklılığı yüksek olan öğrenciler, akademik alanlarda karşılaştığ çok sayıda risklere rağmen bunlarla başarılı şekilde başa çıkabilecek bir güce sahiptirler (Kennedy ve Bennett, 2006, s. 751). Bu öğrenciler okulda engellerle karşılaştığında, akademik konulara ilişkin olarak kendi davranışlarını düzenleyebilir ve okula ilişkin olumlu tutumlarını sürdürebilirler (McTigue, Washburn ve Liew, 2009, s. 423). Akademik dayanıklılığı yüksek olan öğrenciler, okulda başarısız olsalar ya da okulu bırakma 
durumunda kalacak olsalar bile başarı güdülerini ve performans düzeylerini sürekli artırabilirler (Alva, 1991; Aktaran, Martin ve Marsh, 2006, s. 267). Akademik dayanıklılık, okuldan hoşlanma, derslere katılma, öz yeterlik, öğrenme yönelimli olma, okula verilen değer, planlama, çalışma yönetimi, sebatkârlık ile olumlu olarak ilişkilendirilken, kendini engelleme, kaygı ve başarısızlıktan kaçınma ile olumsuz olarak ilişkilendirilmiştir (Martin ve Marsh, 2006, s. 271). Ayrıca, akademik dayanıklığı yüksek öğrenciler, dayanıklı olmayan yaşıtlarından daha çok ödev yapmakta ve daha çok çalışmaktadırlar (Finn ve Rock, 1997, s. 231). Akademik dayanıklılığ yüksek öğrenciler, geleceğe dönük hedefler koyarlar. Bu hedeflerine ulaşmada, gerekli akademik başarı için çevresel desteklerinin de olduğuna inanırlar (Rouse, 2001, s. 468). Akademik dayanıklılığı yüksek olan bireylerin, akademik süreçte karşılaştıkları problemlerle baş etmede iyidirler.

\section{Bu çalışma}

Ebeveyn başarı baskısı, sınav kaygısını artıran faktörlerden birisidir. Ebeveynleri tarafından başarı baskısına maruz kalan öğrencilerin sınav kaygısının yüksek olduğu görülmüştür (Chen, 2012, s. 238; Kapıkıran, 2016, s. 74). Bununla beraber, sınav kaygısının başarı üzerindeki olumsuz rolü bilinmektedir (Koutsoulis ve Campbell, 2001, s. 120). Ayn1 zamanda, ebeveyn baskısının akademik başarı ile olumsuz (Levpuscek, Zupancic ve Socan, 2013, s. 538), sınav kaygıs1 ile pozitif yönde ilişkilidir (Putwain, Woods ve Symes, 2010, s. 146). Aksine, çocuklarının başarılı olması için güdüleyen, okul çalışmalarına katılan, başarılı olması için gerekli ev düzenlemeleri yapan ve araçsal yönde destekleyici olan ebeveynlerin (yetersizlik algıladığı derslere yardım gibi) çocuklarının sınav kaygısının düşük olduğu bulunmuştur (Leung, Yeung ve Wong, 2010, s. 95; Xiao, 2013, s. 64). Sinav kaygis1 yalnızca sinav anında ortaya çıkmaz. Sınav kaygısı gelecekte olası sınavlara yönelik olarak da ortaya çıkabilir. Bununla birlikte öğrencilerin sınav kaygısına yol açan veya engelleyen ebeveyn davranışları (baskı ve destek) arasında aracı bir rol oynayan değişkenlerin olup olmadığının bilinmesine gereksinim vardır. Ebeveynleri tarafından baskı yapılan risk grubundaki öğrencilerin olası sınav kaygılarını azaltmaya yönelik bir değişkenin olup olmadığı önemlidir. Ayrıca, ebeveynleri tarafından başarı desteği sağlanan öğrencilerin sınav kaygılarını azaltmada başka faktörlerin aracı olup olmadığının da araştırılmasına da ihtiyaç vardır.

Akademik dayanıklığg yüksek olan öğrenciler sınav kaygısıyla baş edebilecek güce sahip olduklarından çoğunlukla verimleri düşmemektedir. Dolayısıyla, ebeveyn başarı baskısı ve desteğinin sınav kaygısı üzerinde doğrudan etkisinin, akademik dayanıklılığın aracılığının teorik ve pratik bir öneme sahip olup olmadığının bilinmesine gereksinim bulunmaktadır. Bu çalışmanın alt yapısını ebeveyn akademik başarı baskısı-desteği, sınav kaygısı ve akademik dayanıklılık arasındaki ilişkilere odaklanan çalışmalar oluşturmuştur. Örneğin, yapılan çalışmalarda ebeveyn akademik başarı desteği ile sınav kaygısı arasında olumsuz (Leung, Yeung, ve Wong, 2010, s. 95; Xiao, 2013, s. 64; Ringeisen ve Raufelder, 2015, s.72), ebeveyn akademik başarı baskısı ile sınav kaygısı arasında olumlu (Chen, 2012, s. 241; Besharat 2003, s. 1052; Putwain vd., 2010, s. 146; Ringeisen ve Raufelder, 2015, s.72) ve ebeveyn desteği ile akademik dayanıklılık arasında olumlu (Kapıkıran, 2012, s. 480) ilişkiler elde edilmiştir. Bu değişkenlerle ilişkili veya benzer kavramların ele alındığı bazı başka çalışmalar da vardır. Örneğin, akademik dayanıklılık ile önemli ölçüde benzerlik taşıyan "akademik güçlüklerle başa çıkma gücünün (academik buoyancy)" öğrenme stratejileri ile sınav kaygısı arasında tam arac1 bir role sahip olduğu saptanmıştır (Collie, Ginns, Martin ve Papworth, 2017, s. 958). Ebeveyn 
başarı baskısı ve desteğinin, sınav kaygısı ile okula bağlılı̆̆1 arasında kısmi aracı olduğu bulunmuştur (Raufelder, vd., 2015, 3750-3751). Martin ve Marsh'a (2006, s. 274) 'a göre, akademik dayanıklılık hayati bir aracı değişkendir.

Yukarıda belirtilen değişkenler arasındaki ilişkilerin doğasının belirlenmesi, psikolojik danışmada ve ilgili alan yazın araştırmaları için yararlı sonuçlara varabilmesini sağlayabilir. Eğer akademik dayanıklılı̆̆ın ebeveyn başarı baskısı- desteği ve sınav kaygısı arasında doğrudan ve dolaylı rolüleri varsa okul psikolojik danışmanlarının bu konular üzerinde daha güçlü çalışarak bir şekilde doğru müdahalelerde bulunabilirler. Bu araştırmalar ve kuramsal açıklamalar ışı̆̆ında,

1. Akademik dayanıklılığınk, ebeveyn başarı baskısı ile sınav kaygısı arasında aracı bir rolü var mıdır?

2. Akademik dayanıklılı̆̆ın ebeveyn başarı desteği ile sınav kaygısı arasında aracı bir rolü var midir?

3. Ebeveyn başarı baskısı ve ebeveyn başarı desteği, sınav kaygısı ve akademik dayanıklılık değişenlerinin doğrudan ilişkisi var mıdır?

Sorularını yanıtlamak amacıyla Şekil 1'de önerilen model sınanacaktır.

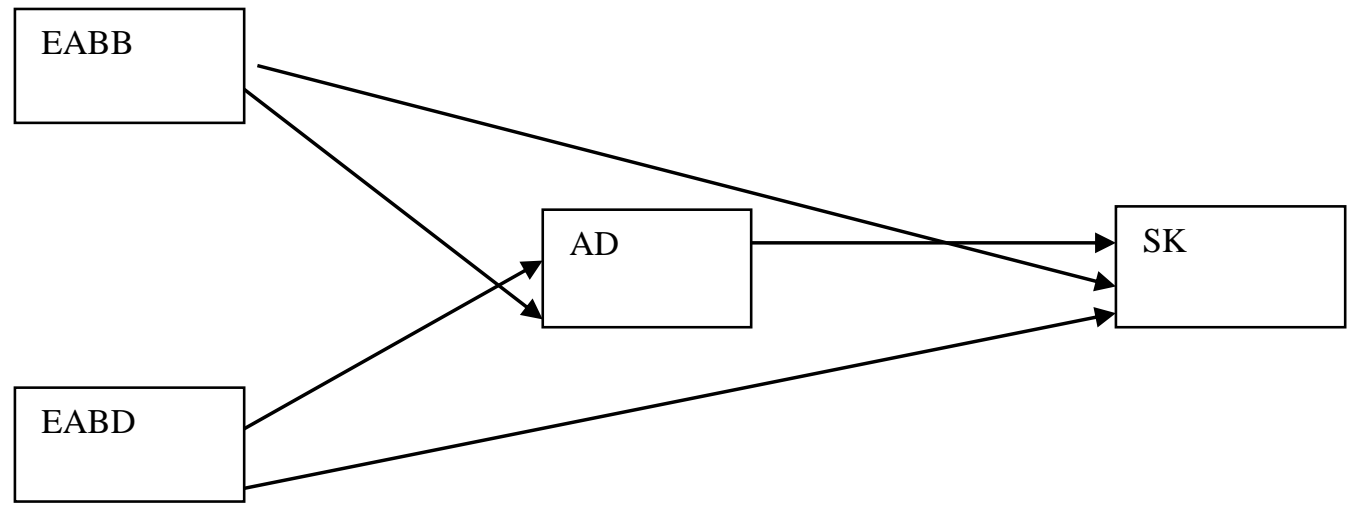

Şekil 1. Akademik Dayanıkııı̆ın Ebeveyn Akademik Başarı Baskısı ve Desteği ile Sınav Kaygısı Arasındaki İlişkide Aracılık Rolüne İlişkin Önerilen Model

$\mathrm{SK}=$ Sınav Kaygısı: $\mathrm{AD}=$ Akademik Dayanıklılık; EABB $=$ Ebeveyn Akademik Başarı Baskısı; EABD = Ebeveyn Akademik Başarı Desteği

\section{Yöntem}

\section{Çalışma Grubu}

Lise öğrencileri üzerinde yapılması hedeflenen bu çalışma için ilk önce İl Milli Eğitim Müdürlügü̈'nden Anadolu Liselerine devam eden öğrenci sayıları istenmiştir. Daha sonra hangi Anadolu liselerinde uygulama yapılacağı belirlenerek ölçme araçlarının uygulanması için izin talebinde bulunulmuştur. Araştırmanın evreni, İl'de bulunan tüm Anadolu liselerini kapsamakta olup, 2016-2017 öğretim y1lı bahar yarıyılında Denizli İl merkezinde öğrenim gören toplam 6635 öğrenciden oluşmaktadır. Araştırma grubu, il merkezinde bulunan 14 anadolu lisesinden, lise giriş sınavları sıralamasında düşükden yükseğe doğru, bir en düşük, bir ortalama ve bir de 
yüksek sıralamaya sahip üç lise belirlenmiştir. Her bir lisede, öğrenci sayıları dikkate alınarak, kaç şubeden öğrenci alınacağı belirlenmiştir. Bu aşamadan sonra, okul rehber öğretmenleri aracılı̆̆ 1 ile sınıflarında uygulama yapılmasına izin veren öğretmenlerin derslerinde uygulama yapılmıştır. Ölçeklerin uygulaması araştırmacıların gözetiminde toplanmıştır. Öğrencilerin ölçek sorularına ilişkin soruları yanıtlanmıştır. Ölçme araçlarının uygulanması yaklaşık 15 dakika sürmüştür. Üç Anadolu Lisesinden toplam 403 öğrenciye ulaşılmıştır. Veri girişi sırasında rastgele doldurulmuş ve çok sayıda boş bırakılmış soru maddeleri olan 13 formun veri girişi yapılmıştır. Araştırma grubu 390 lise öğrencisinden oluşmuştur. Araştırma grubunu oluşturan öğrencilerin cinsiyete göre dağılımı 223 (\% 57.2) kız ve 167 (\% 42.8) erkektir. Çalışma grubu öğrencilerinin yaşları 15-20 arasında değişmektedir $(\overline{\mathrm{x}}=16.70, \mathrm{SD}=.928)$. Sinıf düzeylerine göre; 130 öğrenci (\% 33.3) 9. sınıf, 110 öğrenci ( $\%$ 28.2) 10. sınıf, 103 öğrenci (\% 26.4) 11. sinıf ve 47 öğrenci (\%12.1) 12. sinıfta öğrenim görmektedir. 12. sinıf öğrencileri, sınava hazırlık sürecinde olduğu için şubelerde uygulama yapılmasına öğretmenleri tarafından izin verilmediği için ölçek uygulanan öğrenci sayısı düşük oranda kalmıştır.

\section{Çalışmada Kullanılan Ölçme Araçları}

\section{Kişisel bilgi formu}

Öğrencilerin cinsiyeti, sınıfı ve yaşlarının sorulduğu bir anketle kişisel bilgileri elde edilmiştir.

\section{Akademik dayanıklılık ölçeği (ADÖ)}

Akademik Dayanıklılık Ölçeği, lise öğrencilerinin, güçlüklerle karşılaşmalarına rağmen akademik çalışmalarına güçlü bir şekilde devam eden öğrencileri saptamak amacıyla Martin ve Marsh (2006) tarafından geliştirilmiştir. Akademik Dayanıklılık Ölçeği altı maddeden oluşmaktadır. Ölçüm aracı, "Benim için gerçek değil" den(1 puan) "Benim için son derece gerçek"e (7 puan) arasında değişen 7'li Likert tipinde puanlamayı gerektiren bir ölçektir. Ölçeğin doğrulayıcı faktör analizi sonucunda elde edilen uyum değerleri iyi düzeyde olduğu bulunmuştur ( $\mathrm{CFI}=.98 \mathrm{NNFI}=.96)$. Ölçeğin güvenilirliği için yapılan Cronbach Alfa katsayısı .89 olarak hesaplanmıştır. Ölçeğin toplam madde korelasyonu .59 ile .78 arasında değişmiştir. Ölçeğin Türkçe geçerliliği ve güvenirliği Kapıkıran (2012) tarafından yapılmıştır. Ölçeğin Türkçe yapısını test etmek için açımlayıcı ve doğrulayıcı faktör analizleri yapılmıştır. Ölçeğin açımlayıcı faktör analizi sonucu, ölçek maddelerinin. 70 ile .83 arasında ve DFA için ölçeğin faktör yükleri, 76 ile 92 arasında değişen faktör yüklerine sahip olduğu bulunmuştur. Ölçeğin doğrulayıcı analizi sonucu, $\mathrm{GFI}=.98, \mathrm{AGFI}=.95, \mathrm{SRMR}=.0 .036, \mathrm{RMSEA}=.068 \mathrm{CFI}=.98$ and NNFI = .96.uyum değerleri ile iyi düzeye olduğu saptanmıştır. Ölçeğin güvenirliği için hesaplanan Cronbach Alfa katsayısı .89, üç haftalık aralık ile yapılan test tekrar test güvenilirliği $\mathrm{r}=.82$ olarak hesaplanmıştır. Bu çalışma için hesaplanan alfa katsayısı .82 olarak bulunmuştur.

\section{Sınav kaygısı ölçeği (SKÖ)}

Bu araştırmada sınav kaygısı, Güdülenme ve Öğrenme stratejileri ölçeğinin (GÖSÖ) alt ölçeği olan Sınav Kaygısı Ölçeği kullanılarak ölçülmüştür. GÖSÖ, Pintrich, Smith, Garcia ve McKeachie (1994) tarafından geliştirilmiştir. Tüm ölçek iki ana bileşenden oluşmaktadır: Güdülenme ve Öğrenme Stratejileri. Bu iki bileşende toplam 15 alt ölçek vardır. Ölçek, 7'li puanlamayı gerektiren Likert türündendir. Sınav kaygısı ölçeği güdülenme bileşeni içinde yer almakta olup beş maddeden oluşmaktadır. Ölçeğin iç tutarlılığı için hesaplanan Cronbach Alfa katsayısı .62 - .90 arasında değiştiği bulunmuştur. Ölçek ilk olarak Çakmak, Akgün, Karadeniz, 
Büyüköztürk, ve Demirel (2008) tarafından Türkçeye çevirisi ve doğrulayıcı faktör analizi yapılmıştır. Doğrulayıcı faktör analizi sonucu hesaplanan uyum indeksleri kabul edilebilir düzeye ulaşmıştır. Daha sonra Ölçeğin Türk lise öğrencileri için geçerliği ve güvenirliği Erturan-İlker, Arslan ve Demirhan (2014) tarafından yapılmıştır. Çalışma için yapılan doğrulayıcı faktör analizi sonucu uyum göstergelerinin kabul edilebilir ve iyi düzeyde ( $\chi 2$ /df: 3.93; RMSEA: 0.042; SRMR: 0.047; CFI: 0.95; GFI: 0.90; AGFI: 0.90; NFI: 0.94) olduğu kaydedilmiştir. Ölçeğin iç tutarlılığı için hesaplanan Cronbach Alfa katsayısı toplamda .88 olarak hesaplanmış ve alt ölçekler için .75 ila .77 arasında değişmiştir. Sınav kaygısı alt ölçeğinin iç tutarlılığı .77 olarak hesaplanmıştır. Bu çalışma için hesaplanan cronbach alfa katsayıs1 .92 olarak hesaplanmıştır.

\section{Ebeveyn akademik başarı baskısı ve destek ölçeği (EABBDÖ)}

Ölçek, ebeveynlerinin çocuklarının akademik başarılarıyla ilgili olarak baskıcı ya da destekleyici davranıp davranmadıklarına yönelik algılarını ölçmek amacıyla Kapıkıran (2016) tarafindan geliştirilmiştir. Ölçeğin psikometrik özellikleri ortaokul ve lise öğrencileri üzerinde gerçekleştirilmiştir. Ölçek, beşli likert türündendir. Ölçeğin yapı geçerliği, açımlayıcı ve doğrulayıcı faktör analizi ile yapılmıştır. Ölçeğin yapı geçerliği için yapılan açımlayıcı faktör analizi sonucu tek faktörlü yapının, .60 düzeyinde açıklayıcı bir güce sahip olduğu saptanmıştır. Ölçek maddelerinin. 50 ile .75 arasında değişen faktör yükü olduğu kaydedilmiştir. Ölçeğin doğrulayıcı faktör analizi sonucunda, RMSEA .070, SRMR, .070, CFI .92 olarak bulunmuştur. Ayrıca ayırt edici ve bileşen geçerliği için, EABB ve EABD alt ölçekleri ile benlik saygısı, hedef yönelimi, motivasyon, sınav kaygısı arasındaki korelasyon hesaplanmıştır. Sonuçta, 10 maddeden oluşan ebeveyn akademik başarı baskısı (EABB) ve 5 maddeden oluşan ebeveyn akademik başarı desteği (EABD) alt ölçeklerinden oluştuğu belirlenmiştir. Ölçeğin iç tutarlılığ 1 için Cronbach Alfa katsayısı EABBÖ için .84, EABDÖ .71 ve tüm maddeler için .82 olarak hesaplanmıştır. Bu çalışmada, Cronbach Alfa katsayısı EABB için .87 ve EABDÖ için .78 olarak hesaplanmıştır.

\section{Analizler ve işlem}

Araştırmanın verilerinin betimleyici istatistikleri SPSS 14 paket program ile analiz edilmiştir. Değişkenler arasındaki muhtemel çoklu doğrusallık sorununu ortadan kaldırmak için öncelikle veriler z puanları ile standartlaştırılmıştır. Değişkenlere ait verilerin, Cronbach Alfa, ortalama, standart sapma, basıklık ve çarpıklıklarına ilişkin betimleyici analizleri yapılmıştır. Değişkenlerin iç tutarlı̆̆ cronbach alfa katsayısı ile hesaplanmıştır. Tüm değişkenlerin iç tutarlılığı iyi düzeyde olduğu bulunmuştur. Ayrıca, Tablo 1 de görüldüğg̈ gibi verilerin dağılımının normalliğini değerlendirmek için yapılan basıklık ve çarpıklığa ilişkin değerler, \% 5 anlamlılık düzeyinde -2.00 ile $+2,00$ değerleri arasında yer almıştır (Cain, Zhang ve Yuan, 2017, s. 1723). Aracılık analizi LISREL 8.71 paket programı ile yapısal eşitlik modeli prosedürlerine uygun olarak yapılmıştır. Aracılık analizi için, Baron ve Kenny (1986) tarafından ileri sürülen dört ölçüt dikkate alınmıştır. Baron ve Kenny'ye (1986) göre, ilk olarak bağımlı değişken (Ebeveyn akademik başarı baskısı ve ebeveyn akademik başarı desteği) aracı değişkenle (Akademik dayanıklılık) ilişkili olmalıdır. İkincisi, bağımsız değişken (Ebeveyn akademik başarı baskısı ve ebeveyn akademik başarı desteği) ile bağımlı değişkeni (Sınav kaygısı) ilişkili olmalıdır. Üçüncüsü, bu eşitlikte bağımlı değişken kontrol edilmesiyle, aracı değişken ile bağımsız değişken ilişkili olmalıdır. Dördüncüsü bağımlı değişken ve bağımsız değişken arasındaki ilişkiye aracı değişken girdiğinde bu ilişki (bağımsız değişken-bağımlı değişken 
ilişkisi) ya anlamlı düzeyde ancak daha düşük olmalı (kısmi aracılık) ya da ilişki artık anlamlı düzeyde olmamalıdır (tam aracılık).

Aracılık analizi, Anderson ve Gerbing (1988)'in önerdiği gibi, ölçüm modeli ve yapısal model olmak üzere iki aşamalı olarak yapılmıştır. Birinci aşamada ölçüm modeliyle, veriler arasında kabul edilebilir bir uyumun var olup olmadığını belirlemek için doğrulayıcı faktör analizi yapılmıştır. İkinci aşamada gizil yapılar arasındaki yapısal ilişkiler test edilmiştir. Bu aşamada üç ayrı analiz yapılmıştır. İlk aşamada, doğrudan ilişkilerin yer aldığı yapıya ilişkin analiz yapılmıştır. İkinci aşamada önerilen yapının desteklenip desteklenmediğini belirlemek amacıyla tüm değişkenlerin yer aldığı kısmi analiz yapılmıştır. Üçüncü aşamada doğrudan ilişkilerin yer almadığı dolaylı ilişki modeli olan tam aracılık analizi yapılmıştır. Doğrulayıcı faktör analizi için her bir ölçekte bulunan maddeler gözlenen değişkenler ve ölçeklerin her biri gizil değişken olarak ele alınmıştır. Çalışma 26 gözlenen ve 4 gizil değişkenden (EABB, EABD, AD, SK) oluşan bir modelden oluşmaktadır. Yapısal eşitlik modeline dayalı olarak yapılan analiz için uygun değerler Hu ve Bentler (1999)' in RMSEA için .06 ve altında değerler iyi, .08 ve altında ise kabul edilebilir, SRMR .08 ve altında ise iyi. 10 ve altında ise kabul edilebilir, CFI, NNFI gibi uyum göstergeleri .95 ve üstü iyi .90 ve üstü kabul edilebilir bir uyumun göstergesi olarak kabul edileceğine dair ölçütü dikkate alınmıştır.

Ayrıca, ebeveyn akademik başarı baskısı ve desteğinin öğrencilerin sınav kaygısı üzerindeki doğrudan rolü ile akademik dayanıklılığın aracılık rolünün anlamlığını test etmek ve dolaylı etkilerini hesaplamak için Delta yöntemi (Sobel, 1982) kullanılmıştır.

\section{Bulgular}

\section{Betimleyici İstatistikler ve Değişkenler arası İlişkiler}

$\mathrm{Bu}$ çalı̧̧mada, akademik dayanıklılı̆̆ı ebeveyn başarı baskısı ve desteğinin sınav kaygısı arasında aracı rolü test edilmiştir. Öncelikle çalışmada yer alan değişkenlerin her birinin birbirleriyle ilişkileri ve iç tutarlılığı hesaplanmıştır. Değişkenler arasındaki ilişkileri belirlemek için Pearson momentler çarpımı korelasyon analizi yapılmıştır. Değişkenlerin birbirleriyle düşük ve orta düzeyde ilişkisi olduğu saptanmıştır (Tablo 1). Sonuç olarak, bu çalışmadaki her bir değişkenin birbiriyle ilişkili olduğu tespit edilmiştir.

Tablo 1. Çalışmanın Tüm Değişkenlerinin Birbirleriyle Korelasyonları ve Betimleyici İstatistikleri $(\mathbf{N}=\mathbf{3 9 0})$

\begin{tabular}{lcccc}
\hline Ölçümler & 1 & 2 & 3 & 4 \\
\hline Sinav kaygısı (SK) & 1 & & & \\
EABB & $.23^{* *}$ & 1 & & \\
EABD & $-.16^{* *}$ & $-.35^{* *}$ & 1 & 1 \\
Akademik Dayanıklılk (AD) & $-.29 * *$ & $-.15^{* *}$ & $.23^{* *}$ & 24.21 \\
Ortalama & 18.52 & 25.25 & 20.53 & 5.02 \\
Ss & 7.35 & 9.42 & 4.08 & .82 \\
$\alpha$ & .92 & .87 & .78 & -.401 \\
Basıklık & .078 & .404 & -1210 & -.293 \\
Çarpıklik & -1.190 & -.479 & 1.231 &
\end{tabular}

Not. EABB = Ebeveyn Akademik Başarı Baskısı; EABD = Ebeveyn Akademik Başarı Desteği

\section{Ölçüm modeli}


Birinci aşamada, önerilen modelin desteklenip desteklenmediğini belirlemek amaciyla doğrulayıcı faktör analizi yapılmıştır. Yapılan analiz sonucunda modelin tüm uyum değerlerinin kabul edilebilir ile iyi arasında değişen düzeyde olduğu kaydedilmiştir [( $\mathrm{x}^{2} / \mathrm{df}(846.86 / 293$ $=3.06), \mathrm{N}=390, \mathrm{p}=.001, \mathrm{CFI}=.93 ; \mathrm{NNFI}=.92, \mathrm{RMSEA}=.070, \mathrm{SRMR}=.064 ; \% 90$ güvenirlik aralığ $[\mathrm{CI}]=.064-.075)]$. Tüm bu değerler kabul edilebilir düzeydedir (Hu ve Bentler, 1999, s. 1).

Tablo 2 Ölçüm Modeli Faktör Yükleri

\begin{tabular}{llllll}
\hline Gizil Değişkenler & S+FY & S-FY & SH & T \\
\hline 1. & SK1 & .80 & 1.70 & .36 & 18.98 \\
2. & SK2 & .92. & 1.99 & .16 & 23.57 \\
3. & SK3 & .89 & 1.95 & .21 & 22.27 \\
4. & SK4 & .67 & 1.37 & .55 & 14.81 \\
5. & SK5 & .97 & 1.89 & .06 & 25.99 \\
1 & AD1 & .44 & .78 & .81 & 7.81 \\
2 & AD2 & .49 & .86 & .76 & 8.79. \\
3 & AD3 & .52 & .84 & .73 & 9.51 \\
4 & AD4 & .61 & 1.07 & .63 & 11.31 \\
5 & AD5 & .58 & 1.18 & .67 & 10.63 \\
6 & AD6 & .63 & 1.11 & .60 & 11.71 \\
1 & EABB1 & .70 & .86 & .51 & 15.10 \\
2 & EABB2 & .63 & .94 & .61 & 13.07 \\
3 & EABB3 & .60 & .87 & .64 & 12.39 \\
4 & EABB4 & .63 & .94 & .60 & 13.26 \\
5 & EABB5 & .75 & 1.04 & .44 & 16.45 \\
6 & EABB6 & .60 & .67 & .63 & 12.48 \\
7 & EABB7 & .72 & 1.00 & .48 & 15.65 \\
8 & EABB8 & .68 & .97 & .54 & 14.46 \\
9 & EABB9 & .58 & .89 & .66 & 11.90 \\
10 & EABB10 & .47 & .63 & .77 & 9.38 \\
1 & EABD1 & .71 & .60 & .36 & 14.32 \\
2 & EABD2 & .71 & .80 & .65 & 14.39 \\
3 & EABD3 & .60 & .79 & 1.06 & 11.37 \\
4 & EABD4 & .61 & .78 & 1.00 & 12.05 \\
5 & EABD5 & .66 & .66 & .57 & 13.21 \\
\hline
\end{tabular}

$\mathrm{S}+\mathrm{FY}=$ Standart Edilmiş Faktör Yükleri; S-FY = Standardize Edilmemiş Faktör Yükleri; $\mathrm{SH}=$ Standart Hata; SK = Sinav Kaygısı: AD = Akademik Dayanıklılık; EABB = Ebeveyn Akademik Başarı Baskısı; EABD = Ebeveyn Akademik Başarı Desteği

\section{Yapisal model}

Yapısal modeli test etmek için üç aşamalı bir yol izlenmiştir (Anderson ve Gerbing 1988, s. 418-421). İlk aşamada, yordayıcı değişkenler (EABB ve EABD) ile yordanan değişken (SK) arasındaki doğrudan etki test edilmiştir. Yordayıcı değişken ebeveyn akademik başarı baskısı ve ebeveyn akademik başarı desteği ile sınav kaygısı arasındaki doğrudan ilişkiye ait indeksler kabul edilebilir ile iyi uyum değerleri arasında değişmiştir [( $\mathrm{x}^{2} / \mathrm{df}(929.73 / 297=3.13), \mathrm{N}=390$, $\mathrm{p}=.001, \mathrm{CFI}=.93 ; \mathrm{NNFI}=.91, \mathrm{RMSEA}=.074 \mathrm{SRMR}=.091 ; \% 90$ güvenirlik aralı̆̆ $[\mathrm{CI}]=$ 
.069-.079)]. Bu ilişkide, EABB ile sınav kaygısı arasında $(\beta=.21, \mathrm{P}<.01)$ ve EABD ile sınav kaygısı arasında $(\beta=-.13, \mathrm{P}<.05)$ anlamlı düzeyde ilişki kaydedilmiştir (Şekil 2).

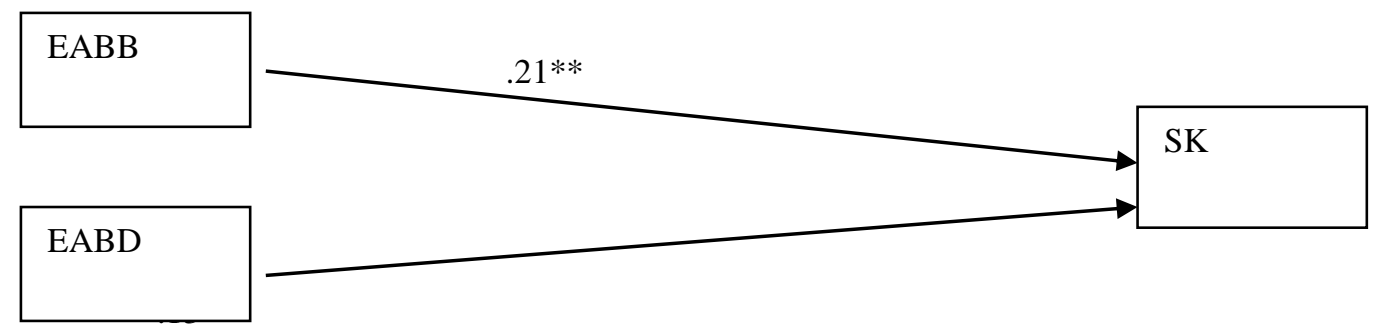

Şekil 2. Ebeveyn Akademik Başarı Baskısı ve Ebeveyn Akademik Başarı Desteğinin Sınav Kaygısı üzerindeki doğrudan rolü

$\mathrm{N}=390, \mathrm{P}=.05^{*}, .01^{* *}$

$\mathrm{SK}=$ Sınav Kaygısı EABB $=$ Ebeveyn Akademik Başarı Baskısı; EABD $=$ Ebeveyn Akademik Başarı Desteği

İkinci aşamada, kısmi aracılık modeli test edilmiştir. $\mathrm{Bu}$ aşamadaki analizde, bağımsız değişkenler, bağımlı değişken ve aracı değişkenlerin tümü yer almıştır. Bu modelde bağımlı değişkenler ile bağımsız değişken arasındaki doğrudan ilişki sınanmaz. Sonuçta, modelin kabul edilebilir ve iyi düzeyde uyum değerlerinde $\left[\left(\mathrm{x}^{2} / \mathrm{df}(846.86 / 293=3.06), \mathrm{N}=390, \mathrm{p}=.01, \mathrm{CFI}=\right.\right.$ $.93 ; \mathrm{NNFI}=.92$, RMSEA $=.070$, SRMR $=.064 ; \% 90$ güvenirlik aralı̆̆ $[\mathrm{CI}]=.064-.075)]$ olduğu bulunmuştur. $\mathrm{Bu}$ modelde, EABB ile $\mathrm{AD}$ arasında olumsuz $(-.14, \mathrm{P}=.05)$, EABD ile $\mathrm{AD}$ arasinda olumlu $(.23, \mathrm{P}<.01)$ ve $\mathrm{AD}$ ile $\mathrm{SK}$ arasında olumsuz $(-.36, \mathrm{P}<.01)$ yönde anlamlı düzeyde ilişki saptanmıştır (Tablo, 3 )

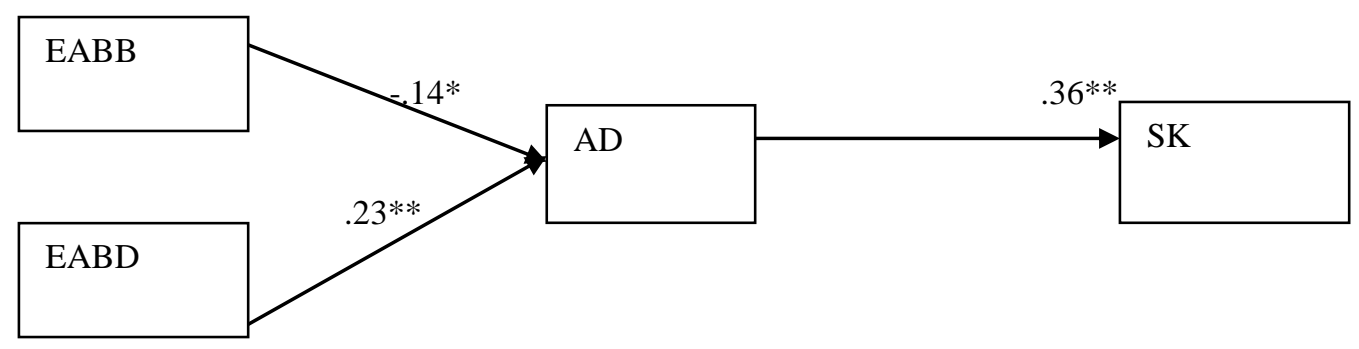

Şekil 3. Ebeveyn Akademik Başarı Baskısı ve Ebeveyn Akademik Başarı Desteğinin Sınav Kaygısı arasındaki aracılık rolü (Tam aracılık model)

$\mathrm{SK}=$ Sınav Kaygısı: $\mathrm{AD}=$ Akademik Dayanıklılık; EABB $=$ Ebeveyn Akademik Başarı Baskısı; EABD = Ebeveyn Akademik Başarı Desteği

Üçüncü aşamada, tam aracılık model test edilmiştir. Bu aşamada, aracı değişkenin (akademik dayanıklı1ık) bağımsız değişken (ebeveyn akademik başarı baskısı ve ebeveyn akademik başarı desteği) ve bağımlı değişken (sınav kaygısı) arasında aracı olup olmadığı test edilmiştir. Bu modelde, bağımsız değişkenlerle bağımlı değişken arasındaki ilişkiye yer verilmiştir. Sonuçta tam arac1lik modelin $\left[\left(\mathrm{x}^{2} / \mathrm{df}(852.82 / 295=2.89), \mathrm{N}=390, \mathrm{p}=.01, \mathrm{CFI}=\right.\right.$ 
$.93 ;$ NNFI $=.92$, RMSEA $=.070$, SRMR $=.074 ; \% 90$ güvenirlik aralı̆̆ $[\mathrm{CI}]=.064-.075)]$ kabul edilebilir ve iyi düzeyde uyum indekslerine sahip olduğu görülmüştür. Bu modeldeki ilişkilere bakıldığında, EABB ile AD arasında $(\beta=-.14, \mathrm{P}<.05)$, EABB ile SK arasında $(.21, \mathrm{P}$ $<.01)$, EABD ile AD arasinda $(\beta=.23, \mathrm{P}<.01)$, EABD ile SK arasinda $(\beta=.-.13, \mathrm{P}<.05)$, ilişkiler elde edilmiştir (Şekil, 4). Bununla birlikte, ebeveyn akademik başarı baskısı ile sınav kaygısı ve ebeveyn akademik başarı desteği ile SK arasındaki ilişki istatistiksel olarak anlamlı bulunmuştur. Daha sonra ebeveyn akademik başarı baskısı ve ebeveyn akademik başarı desteği ile sınav kaygısı arasına akademik dayanıklılık katıldığında (kısmi aracılık), ebeveyn akademik başarı baskısı ile sınav kaygısı arasındaki ilişkide bir miktar düşme olsa da, bu ilişki hala anlamlıydı $[(\beta=.21, \mathrm{P}<.01)$ den $(\beta=.17, \mathrm{P}<.01)]$. Ancak akademik dayanıklılık aracı değişken olarak modele katıldığında, ebeveyn akademik başarı desteği ile sınav kaygısı arasındaki ilişkide önemli ölçüde düşme görülmüştür. Diğer bir deyişle akademik dayanıklılık EABD ile SK arasında tam aracılığa sahiptir $[\beta=-.13, \mathrm{P}<.05)$ den $(\beta=-.03, \mathrm{P}>.05)]$ (Şekil 4).

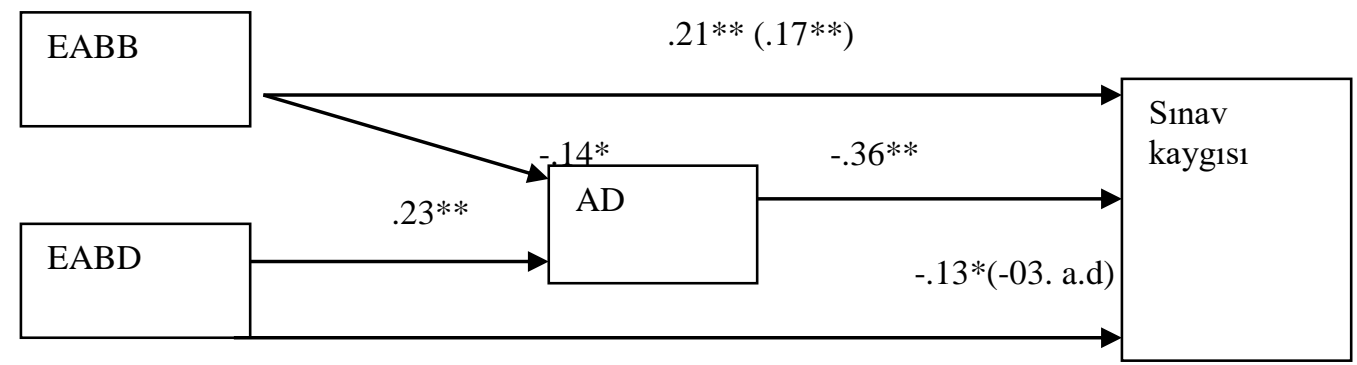

$\mathrm{P}=* .05, * * .01$

Şekil 4. Akademik Dayanıkııı̆ın Ebeveyn Akademik Başarı Baskısı ve Desteği ile Sınav Kaygısı Arasındaki İlişkide Aracılık Rolü

$\mathrm{AD}=$ Akademik Dayanıklılık EABB $=$ Ebeveyn Akademik Başarı Baskısı; EABD $=$ Ebeveyn Akademik Başarı Desteği

Yapısal model üç aşamalı olarak analiz edildikten sonra, modelin iyi bir model olup olmadığını belirlemek üzere, kısmi ve tam aracılık model analizleri arasındaki ki kare farkının olup olmadığını belirlemek amacıyla ki kare fark testi yapılmıştır (Anderson ve Gerbing 1988, s. 418-421). Sonuçta, kısmi ve tam aracılık modelleri arasındaki ki kare farkının anlamlı düzeyde olmadığı bulunmuştur $\left(\Delta \mathrm{X}^{2}=5.96, \Delta \mathrm{df}=2, \mathrm{P}>.05\right)$. Bu sonuç, önerilen modelin iyi bir model olduğunu göstermektedir. Akademik dayanıklılığın ebeveyn akademik başarı baskısı ve ebeveyn akademik başarı desteği ile sınav kaygısı arasındaki dolaylı rolünü hesaplamak için Delta yöntemi (Sobel, 1982, s. 388) kullanılmıştır. Akademik dayanıklılığın ebeveyn akademik başarı baskısı ve ebeveyn akademik başarı desteği ile sınav kaygısı arasındaki dolaylı rolüne ilişkin temel etkiyi hesaplamak için aracılık testi yapılmıştır (Anderson ve Gerbing, 1998, s. 418-421). Yapılan sobel test sonucu akademik dayanıklılığın ebeveyn akademik başarı baskısı ile sınav kaygısı arasındaki aracılığı anlamlı düzeye ulaşırken, aracılığa ait temel etki .50 ( $\beta=$ =$.14 \times \beta=-.36, Z=-2.130, P<.01)$ olarak saptanmıştır. Akademik dayanıklı1ı̆̆ın ebeveyn akademik başarı desteği ile sınav kaygısı arasındaki aracılığına ilişkin Sobel testi sonucu anlamlı düzeyde olduğu bulunmuştur $(\beta=.23 \times \beta=-.36, Z=-2.681, P<.01)$. Aracılığa ait temel 
etki .82 olarak hesaplanmıştır. Bu model için akademik dayanıklılığın varyansa katkısı \% 19 olurken, sınav kaygısının varyansa katkısı $\% 42$ olarak hesaplanmıştır.

Tablo 3. Kovaryans Yapı Analizleri için Uyum Indeksleri $(\mathbf{N}=390)$

\begin{tabular}{llllllll}
\hline & $\mathrm{X}^{2}$ & $\mathrm{df}$ & NNFI & CFI & RMSEA & SRMR & 90\% CI RMSEA \\
\hline Ölçüm modeli & 846.86 & 293 & .92 & .93 & .070 & .064 & $.064-.075$ \\
Doğrudan ilişki & 929.23 & 297 & .91 & .93 & .074 & .091 & $.069-.070$ \\
Kismi model & 846.86 & 293 & .92 & .93 & .070 & .064 & $.064-.075$ \\
Tam model & 852.82 & 295 & .92 & .93 & .070 & .074 & $.064-.075$ \\
\hline
\end{tabular}

$\mathrm{NNFI}=$ Normalleştirilmemiş Uyum İndeksi, CFI = Karşılaştırmalı Uyum İndeksi, RMSEA = Yaklaşı hataların ortalama kare kökü, SRMR $=$ Standardize Edilmiş Hataların Ortalama Karekökü, CI= Güven aralığı

Sonuç olarak akademik dayanıklılığın, ebeveyn akademik başarı desteği ile sınav kaygısı arasında tam aracılığı olduğu saptanmıştır. Ancak akademik dayanıklılığın ebeveyn akademik başarı baskısı ile sınav kaygısı arasında aracı1ık rolü kısmi düzeyde kalmıştır.

\section{Tartışma}

$\mathrm{Bu}$ çalışmanın amacı, akademik dayanıklılı̆̆ın algılanan ebeveyn akademik başarı baskısı/ebeveyn akademik başarı desteği ve sınav kaygısı arasında aracı bir role sahip olup olmadığının test edilmesidir. Ayrıca, değişkenler arasındaki ilişkilerin düzeyinin saptanması da amaçlanmıştır.

Araştırmada elde edilen ilk bulguya göre, ebeveyn akademik başarı baskısı ile sınav kaygısı arasındaki doğrudan ilişkide pozitif yönde anlamlı bir ilişki saptanmıştır. Bu sonuca göre, ebeveynleri tarafından daha başarılı olması yönünde baskı yapılan ergenlerin sınav kaygıları artmaktadır. Türkiye'de, özellikle lisenin ilk yılından itibaren ebeveynler, çocuklarının daha prestijli bir üniversitede bir bölüm kazanması yönünde beklentilere sahip olurlar. Beklenti gerçekçi olduğunda çocuklarının başarısı üzerinde olumlu etki yapabilir. Ancak, bazı ebeveynler çocuklarından gerçekçi olmayan bir başarı beklentisine sahip olabilmektedirler. Ebeveynler, gerçekçi olmayan bu başarı beklentilerini çocuklarına sıklıkla ve 1srarlı biçimde çalışması gerektiği yönünde yansıtırlar. Ebeveynlerin çocuklarından ev ödevi ve ekstra ders çalışması yönündeki 1srarlı beklentileri, çocuklarda baskı olarak algılanmasına neden olabilmektedir. Sarason ve arkadaşları (1960) çocukların sınav kaygısının altında yatan nedenin, ebeveynlerinin beklentileri olduğunu ileri sürmüşlerdir (Aktaran, Mcdonald, 2001). Bu çocukların beklentiyi karşılamayacağına ilişkin inanç geliştirmesine neden olabilmekte ve çoğu zaman sınav kaygısına dönüşebilmektedir. Dolayısıyla, ebeveynlerin çocuklarına sınavlarda daha iyi performans göstermesi için yaptıkları baskı nedeniyle çocukların sınav kaygıları artmaktadır (Mcdonald, 2001). Ayrıca, başarı baskısı yapılan öğrenciler daha az ders çalıştıkları için ebeveynleri tarafından daha çok baskı yapılması yüzünden kaygıları artabilir (Putwain, vd., 2010). Chen (2012) ergen öğrencilerin ebeveynlerin başarı baskısının, ebeveynlerin sosyal kimliği ile sınav kaygısı arasındaki aracılığına ilişkin çalışmasında, ebeveyn algılanan başarı baskının sınav kaygısı üstünde güçlü bir rolü olduğunu bulmuştur. Ona göre, bu tip ailelerin çocukları akademik olarak mükemmel olmaları yönünde baskı hissettikleri için stres altında olurlar. Bu stres sınav kaygısına dönüşür.

Elde edilen diğer bir bulguya göre, ebeveyn akademik başarı baskısı ile akademik dayanıklılık arasındaki doğrudan ilişkinin olumsuz yönde olduğu bulunmuştur. Akademik 
dayanıklılık, pek çok öğrencinin akademik hayatlarında karşılaştı̆̆ baskı ve zorluklarla ilgilidir (Martin ve Marsh, 2009). Ebeveynlerin çocuklarına yaptıkları akademik başarı baskısı sonucunda, yüksek düzeyde akademik performansa ayak uydurmalarını beklemektedir. Dahası ebeveyn başarı baskısının ergenlerin matematik öz yeterlikleriyle olumsuz yönde ilişkili olduğu görülmüştür (Levpuscek ve Zupancic, 2008). Ebeveynlerin akademik başarı baskısı aynı zamanda ergenlerin okullarına karşı olumsuz tutum göstermesine ve akademik başarısızlıklarına da neden olabilir. Fischer, Bol, Pribesh ve Nunnery (2013), yaptıkları çalışmada ebeveynlerin akademik başarı baskısının, akademik başarı ve akademik katılım üzerinde olumsuz yönde yüksek düzeyde yordayıcı rolü olduğunu bulmuşlardır.

Araştırma bulgularına göre, ebeveyn akademik başarı desteği ile sınav kaygısı arasındaki doğrudan ilişkinin istatistiksel olarak olumsuz yönde anlamlı olduğu bulunmuştur. Buna göre, çocukların akademik başarılarını ebeveynler tarafından desteklendiğinde sınav kaygıları azalmaktadır. Bu bulgu daha önce yapılan çok sayıdaki çalışma tarafından desteklenmektedir (Cutrona, Colangelo, Assouline, ve Russell 1994; Leung, Yeung, ve Wong, 2010; Y1ldırım, 2000). Bazı ebeveynler, çocuklarının başarılı olmaları yönünde beklentilerini ortaya koyarak kendi beklentilerini karşılamaya çalışırlar. Türk kültürü, toplulukçu bir kültür olarak, ailesindeki başarı ve başarısızlıkları ailenin bir ürünü olarak görme eğilimindedir (Kağıtçıbaşı, 1996, 2005). Dolayısıyla, ebeveynler çocuklarının başarılı olması için sıklıkla beklentilerini dile getirebilirler. Verkuyten, Thijs ve Canatan, (2011) Hollandalı ve Türk öğrencilerin akademik başarıları üzerindeki bireysel ve aile yönelimli güdülerini araştırdıkları çalışmalarında, Türk ergenlerin aile yönelimli güdülerinin (family-oriented motivation) daha yüksek olduğunu bulmuşlardır. Araştırmacılara göre, Türk ergenler daha toplulukçu bir kültüre sahiplerken Hollandalı ergenler daha bireyci bir kültüre sahiptirler. Türkler ailelerine karşı daha sadık ve kendilerini aileye karşı daha yükümlü hissetmektedirler. Dolayısıyla, Türkiye gibi daha toplulukçu toplumlardaki ebeveynler, çocuklarından beklentilerini yerine getirmesi için daha destekleyici davranmaktadırlar. Toplulukçu kültürlerdeki ebeveynlerin başarı desteğinin amaçlarından birisi çocuklarının elde edeceği başarıları ile gurur duymaktır. Chen, (2012) göre toplulukçu bir kültüre sahip Çin'de ebeveynler çocuklarının başarılarına yönelik destekleyici davranmalarının nedenlerinden birisinin, çocuklarının elde edecekleri başarıdan gurur duyabilmek olduğunu ileri sürmektedir.

Ebeveyn akademik başarı desteği ile akademik dayanıklılık arasında doğrudan ve pozitif yönde anlamlı bir ilişki kaydedilmiştir. Başka bir deyişle, ebeveyn akademik başarı desteği algılayan ergenlerin, akademik dayanıklılı̆ğ olumlu yönde etkilenmektedir. Öğrencilere sağlanan ebeveyn başarı desteği onların akademik dayanıklılığı üzerinde olumlu katkı yapabilir. Bazı çalışmalarda aileden algılanan soysal destek ve algılanan ebeveyn başarı desteği ile akademik dayanıklılık arasında olumlu yönde ilişki saptanmıştır (Kapıkıran 2012; Koutsoulis ve Campbell, 2001). Ayrıca, aile dışındaki öğretmen ve arkadaş grupları tarafindan sosyal destek sağlanması, okul ile ilgili eğitimsel desteğin verilmesi, akademik dayanıklılığın artırılmasında güçlü bir katkı sağlayabilir. Eğitimsel dayanıklılık ve riskli öğrenciler üzerindeki çalışmalarda, ergenlerin okul başarıları üzerinde aile, yaşıt gruplar, okul ve toplum tarafından sağlanan desteğin koruyucu faktörler olduğu rapor edilmiştir (Bogenschneider, 1996; Richman, Rosenfeld ve Bowen, 1998).

Modelde yer alan ilişkide, aracı değişken olan akademik dayanıklılık ile bağımlı değişken olan sınav kaygısı arasındaki ilişkinin düzeyi incelendiğinde, ortalama düzeyde negatif yönde anlamlı bir ilişki kaydedilmiştir. Akademik dayanıklılığı yüksek olan lise öğrencilerinin 
akademik görevlerle karşı karşıya kaldıklarında ortaya çıkan güçlüklerle yeterince ve etkili olarak başa çıkabildikleri için sınavlara ilişkin daha az kaygı duyarlar. Dolayısıyla yüksek akademik dayanıklılığa sahip bireylerin sınav kaygısı düşmektedir. Bu bulgu daha önceki yapılan araştırmalardan elde edilen bulguları desteklemektedir (Beutel, Glaesmer ve Wilting, 2010; Martin ve Marsh, 2006; Putwain, Nicholson, Connors ve Woods, 2013). Olası ki, yüksek sınav kaygısı olan kişiler bilişsel olarak başarısız olacaklarına ilişkin inanca sahiptirler. Onlar çevresel tehdit ve baskılarla baş etmede güçlük çekerler. Oysa akademik dayanıklılığı yüksek olan kişiler, çevresel tehdit ve baskılarla baş etmede iyidirler.

Araştırmanın temel amaçlarından biri olan akademik dayanıklılığın ebeveyn başarı baskısı-desteği ile sınav kaygısı arasındaki aracılığına ilişkin model sınanması sonucunda kabul edilebilir düzeyde iyi uyum indekslerine sahip olduğu bulunmuştur. İlk olarak, akademik dayanıklılığın ebeveynlerin baskılarından kaynaklanan sınav kaygısı üzerindeki rolüne ilişkin aracılığı kısmi düzeyde desteklenmiştir. Diğer bir deyişle ebeveynleri tarafından akademik başarı baskısı sonucu, öğrencilerin hissettikleri sınav kaygısı üzerinde akademik dayanıklılık yerince güçlü değildir veya ebeveyn akademik başarı baskısının sınav kaygısı üstünde güçlü bir rolü olduğunu göstermektedir. Bireyler karşılaştıkları akademik sorunlarla ve zorluklarla baş edebildikleri sürece akademik dayanıklılıkları artmaktadır. Aksine bireyler akademik sorunlarla baş edemeyeceklerini düşündüklerinde başarısızlık korkuları geliştirebileceklerdir. Bu durum sinav kaygısını arttıracaktır.

Akademik dayanıklılığın ebeveyn akademik başarı desteği ile sınav kaygısı arasında aracılığı için yapılan analiz sonucunda, akademik dayanıklılığın ebeveyn akademik başarı desteği ve sınav kaygısı ilişkisinde tam aracılık rolüne sahip olduğu saptanmıştır. Bu sonuca göre, başarı desteği sağlayan ebeveynler, çocuklarının akademik dayanıklılığını arttırdığı için kayg1 veren durumlarla çocuklar daha etkili başa çıkabilmekte ve bu yüzden akademik durumlarda daha düşük kaygı hissetmektedirler. Diğer bir deyişle, ebeveynlerin akademik başarı desteği, sınav kaygısını düşük düzeyde olmasına neden olmaktadır. Ayrıca, akademik dayanıklılığ 1 yüksek olan bireylerin sınav kaygısı düşmektedir. Yapılan bir çalışmada, duyarlı ebeveynleri olan ergenlerin yoksulluktan kaynaklanan akademik başarı sorunlarına karşı tampon rolü olduğu bulunmuştur (Gregory ve Rimm-Kaufman, 2008). Özellikle ebeveynlerin ve öğretmenlerin dezavantajlı çocuklara yönelik sosyal desteğinin, çocukların başarısı üzerinde olumlu etkisi olduğu kaydedilmiştir (Croninger ve Lee 2001; Malecki ve Demaray 2006). Çalışmalara göre, akademik dayanıklılığı güçlü olan öğrencilerin akademik başarısı yüksek (Wasonga, Christman ve Kilmer, 2003; Cappella ve Weinstein, 2001) ve sinav kaygısı düşüktür (Kapıkıran, 2012). Bununla birlikte, güçlü akademik dayanıklılık sadece çocukların sınav kaygısını etkilemekle kalmaz, aynı zamanda okul başarısına katkıda bulunan katılım ve güdülenme gibi faktörlere de katkıda bulunabilir.

\section{Sinırlılıklar}

$\mathrm{Bu}$ çalışmanın verileri yalnızca belli bir yaş gruplarından toplanmıştır. Yani veriler kesitsel desene dayalı olarak elde edilmiştir. Ayrıca, veriler öz bildirime dayalı ölçme araçları ile toplanmıştır. Dolayısıyla elde edilen veriler ergenlerin doğrudan yaşantılarının bir ürünü değildir. Ergenlerin algılanan ebeveyn akademik başarı baskısı, algılanan ebeveyn akademik başarı desteği, akademik dayanıklılık ve sınav kaygısı ölçümleri, ölçme araçlarına verdikleri yanıtlar, yalnızca o günkü koşulları içindeki duygu ve düşüncelerini yansıtmaktadır. Ayrıca, elde edilen veriler yalnızca Türkiye'nin bir şehrindeki liselerde elde edildiğinden dolayı, elde 
edilen sonuçlar, bütün kültürlere ve farklı yaş gruplarına genellenemez. Son olarak, elde edilen sonuçlar sınırlı bazı özelliklerin ölçümüyle gerçekleştirildiğinden dolayı, neden sonuç ilişkisi kurulamaz. Gelecek çalışmaların bu ilişkileri dikkate alarak yapılması görece neden sonuç ilişkisi bağı kurulmasına yardımcı olabilir.

\section{Sonuç ve Öneriler}

Elde edilen verilerin analizi sonucunda, ebeveynlerin akademik başarı baskısı yapmalarının, sınav kaygısı üzerinde olumsuz bir rolü olduğunu göstermiştir. Diğer bir deyişle, ebeveyn başarı baskısı sınav kaygısını artırmaktadır. Literatüre ve mevcut araştırmanın bu bulgusuna dayanarak, ebeveynlerin çocuklarını kendi başarı standartlarına ulaşmaya zorladığında, çocukların sınav endişesini artırabilir. Ebeveynler, başarılı olmaları için çocuklarına baskı yapmamalıdır. Araştırmamızda elde edilen bir diğer bulgu da, ebeveyn başarı desteği ile sınav kaygısı arasında olumsuz yönde bir ilişkinin saptanmasıdır. Ebeveynler çocuklarının başarılı olması için destek verdiklerinde, sınav kaygısı hissetme oranı azalabilir. Bu nedenle, ebeveynler çocuklarının okul başarısına destek sağlamak için çocuklarının başarılarına güvendiklerini davranışlarıyla göstermeli ve onların bilgi eksikliklerini gidermeye yönelik adımlar atmalıdır. Araştırmada doğrudan ilişkiye ilişkin diğer bir bulgu, ebeveyn başarı baskısı ile akademik dayanıklık arasında olumsuz yönde bir ilişki bulunmuştur. Ergenlere ebeveynleri tarafından yapılan başarı baskısı ciddi psikolojik problemlere de neden olabilir. Riley (2003) tarafından yapılan bir çalışmada, ebeveyn başarı baskısının, depresyon, anksiyete, psikolojik sıkıntılar ve duygusal-davranışsal sorunları artırdığını bulmuştur. Bununla beraber, çalışmamızda, ebeveyn başarı desteğinin öğrencilerin akademik dayanıklılığı üstünde olumlu rolü olduğu bulunmuştur. $\mathrm{Bu}$ sonuca göre, öğrencilikleri süresince stres ve başarısızlık baskısı altında olan öğrencilerin akademik dayanıklılıklarını güçlendirmek için ebeveynlerce destek sağlanmalıdır. Akademik dayanıklılık ile sınav kaygısı arasında negatif bir ilişki vardır. Başka bir deyişle, akademik dayanıklılık arttıkça bireyin sınav kaygısı azalmaktadır.

Bununla birlikte, akademik dayanıklılığın ebeveyn akademik başarı desteği ve sınav kaygısı arasında tam aracılı̆̆ 1 vardır. Bu sonuca göre, yüksek akademik dayanıklılığı olan öğrencilerin ebeveyn akademik başarı desteği yüksek olan öğrencilerin sınav kaygısını düşmektedir. Özellikle güçlüklerle karşıkarşıya kaldıklarında bu güçlükleri aşmaları için duygusal ve davranışsal destekler sunulmalıdır. Dezavantajlı öğrencileri ve akademik dayanıklılığı araştıran bir raporda Türkiye 28 ülke arasında en dezavantajlı ülkeler arasında olduğu rapor edilmiştir. Bununla beraber, akademik dayanıklılık bakımdan da orta düzeydedir (Erberber, Stephens, Mamedova, Ferguson ve Kroeger, 2015). Bu süreçte, okul psikolojik danışmanları öğrencilerin dayanıklılıklarını artırmaya yönelik grup rehberliği ve psikoeğitim programları hazırlayarak öğrencilerin akademik güçlüklerinin üstesinden gelmesine yardım etmelidirler. Aynı zamanda, okul psikolojik danışmanlar öğrenci velilerine akademik dayanıklılık için ebeveyn desteğinin önemine yönelik olarak müşavirlik yapmalıdırlar. Öğrencilerin akademik dayanıklılığını artırmak için ebeveyn desteğinin olması önemlidir. Dolayısıyla, okul psikolojik danışmanları, ebeveynlere başarı baskısı yerine başarı desteği sağlaması yönünde rehberlik etmelidirler. Bu rehberlik çocukların sınav kaygısı riskini, okul tükenmişliklerinin azalmasını sağlayabilir. 


\section{Kaynakça}

Adams, G. R., Ryan, B. A., Ketsetzis, M. ve Keating L. (2000). Psychology rule compliance and peer sociability: A study of family process, school-focused parent-child interactions, and children's classroom behavior. Journal of Family Psychology, 14, 237-250. doi:10.1037/08933200.14.2.237.

Anderson, J. C. ve Gerbing, D. W. (1988). Structural equation modeling in practice: A review and recommended two-step approach. Psychological Bulletin, 103(3), 411-423. doi.org/10.1037/0033-2909.103.3.411.

Balogun, A. G., Balogun, S. K., \& Onyencho, C. V. (2017). Test anxiety and academic performance among undergraduates: The moderating role of achievement motivation. The Spanish journal of psychology, 20. 0, e14, 1-8. doi:10.1017/sjp.2017.5

Beidel, D. C., Turner, M. W. ve Trager, K. N. (1994). Test anxiety and childhood anxiety disorders in African American and White school children. Journal of Anxiety Disorders, 8, 169-179. doi:10.1016/0887-6185(94)90014-0

Besharat, M. A. (2003). Parental perfectionism and children's test anxiety. Psychological Reports, 93, 1049-1055. doi:10.2466/ PR0.93.8.1049-1055.

Beutel, M. E., Glaesmer, H., Wiltink, J., Marian, H. ve Brähler, E. (2010). Life satisfaction, anxiety, depression and resilience across the life span of men. The Aging Male, 13(1), 3239.doi:10.3109/13685530903296698.

Bogenschneider , K. (1996). An ecological risk/protective theory for building prevention programs, policies and community capacity to support youth. Family Relations, 45, 127-138. doi:10.2307/585283.

Bronstein, P., Ginsburg, G. S. ve Herrera, I. S. (2005). Parental predictors of motivational orientation in early adolescence: A longitudinal study. Journal of Youth and Adolescence, 34, 559-575. Doi: 10.1007/s10964-005-8946-0

Cain, M. K., Zhang, Z., \& Yuan, K. H. (2017). Univariate and multivariate skewness and kurtosis for measuring nonnormality: Prevalence, influence and estimation. Behavior research methods, 49(5), 1716-1735. doi: 10.3758/s13428-016-0814-1

Cassady, J. C., ve Johnson, R. E. (2002). Cognitive test anxiety and academic performance. Contemporary Educational Psychology,27(2), 270-295. doi:10.1006/ ceps.2001.1094.

Chapell, M. S., Blanding, Z. B., Silverstein, M. E., Takahashi, M., Newman, B., Gubi, A. ve McCann, N. (2005). Test anxiety and academic performance in undergraduate and graduate students. Journal of Educational Psychology, 97(2), 268-274. DOI: 1037/0022-0663.97.2.268.

Chen, J. J. -L. (2005). Relation of academic support from parents, teachers, and peers to Hong Kong adolescents' academic achievement: The mediating role of academic engagement. Genetic, Social, and General Psychology Monographs, 131, 77-127. doi:10.3200/MONO.131.2.77-127.

Chen, H. (2012). Impact of Parent's Socioeconomic Status on Perceived Parental Pressure and Test Anxiety among Chinese High School Students. International Journal of Psychological Studies, 4, 235-245. doi:10.5539/ijps.v4n2p235

Collie, R. J., Ginns, P., Martin, A. J. ve Papworth, B. (2017). Academic buoyancy mediates academic anxiety's effects on learning strategies: an investigation of English-and Chinese-speaking Australian students. Educational Psychology, 37(8), 947-964. $\quad$ DOI: 10.1080/01443410.2017.1291910.

Croninger, R. G. ve Lee, V. E. (2001). Social capital and dropping out of high school: Benefits to at-risk students of teachers' support and guidance. Teachers College Record, 103, 548-581. doi:10.1111/0161-4681.00127.

Cutrona, C. E., Cole, V., Colangelo, N., Assouline, S. G. ve Russell, D. W. (1994). Perceived parental 
social support and academic achievement: An attachment theory perspective. Journal of Personality and Social Psychology, 66, 369-378. doi:10.1037/0022-3514.66.2.369.

Çakmak, E. K., Akgün, Ö. A., Karadeniz, Ş., Büyüköztürk, Ş. ve Demirel, F. (2008). İlköğretim ikinci kademe ve lise öğrencilerinin ders ve sınıf düzeylerine göre öğrenme stratejileri ve güdülenme düzeylerinin belirlenmesi. Uluslararası Insan Bilimleri Dergisi, 5(1), 1-27. https://www.jhumansciences. com/ojs/index.php/IJHS/article/view/454/285.

Erberber, E., Stephens, M., Mamedova, S., Ferguson, S. ve Kroeger, T. (2015). Socioeconomically Disadvantaged Students Who Are Academically Successful: Examining Academic Resilience Cross-Nationally. Policy Brief No. 5. International Association for the Evaluation of Educational Achievement, 1-12. P. 11. https://files.eric.ed.gov/fulltext/ED557616.

Erturan-Ilker, G., Arslan, Y. ve Demirhan, G. (2014). A validity and reliability study of the motivated strategies for learning questionnaire. Educational Sciences: Theory and Practice, 14, 829-833. doi: 10.12738/estp.2014.3.1871.

Finn, J. D. ve Rock, D. A. (1997). Academic success among students at risk for school failure. Journal of Applied Psychology, 82(2), 221-234. doi/10.1037/0021-9010.82.2.221.

Fischer, C., Bol, L., Pribesh, S. ve Nunnery, J. (2013). Where is the learning in smaller learning Communities? Academic press, social support for learning, and academic engagement in smaller learning community classrooms. Journal of Education for Students Placed at Risk (JESPAR), 18(3-4), 177-192. doi: 10.1080/10824669.2013.811569.

Ginsburg, G. ve Bronstein, P. (1993). Family factors related to children's intrinsic/extrinsic motivational orientation and academic performance. Child Development, 64, 1461-1474. doi: 10.1111/j.1467-8624.1993.tb02964.x.

Gonzalez-DeHass, A. R., Willems, P. P. ve Holbein, M. F. D. (2005). Examining the relationship between parent involvement and student motivation. Educational Psychology Review, 17, 99123. doi: 10.1007/s10648-005-3949-7.

Gottfried, A. E., Fleming, J. S. ve Gottfried, A. W. (1994). Role of parental motivational practices in children's academic intrinsic motivation and achievement. Journal of Education Psychology, 86, 104-113. doi:10.1037/0022-0663.86.1.104.

Gregory, A. ve Rimm-Kaufman, S. (2008). Positive mother-child interactions in kindergarten: Predictors of school success in high school. School Psychology Review, 37(4), 499-515. 18.11.2016 tarihinde erişilmiştir. https://search.proquest.com/openview/4455b41dcd479a2d65f15b9f $\quad 2 \mathrm{a} 9 \mathrm{e} 4 \mathrm{~b} 63 / 1$ ? $\quad$ pqorigsite $=$ gscholar $\& \mathrm{cbl}=48217$,

Güler, D. ve Çakir, G. (2013). Lise son sınıf öğrencilerinin sınav kaygısını yordayan değişkenlerin incelenmesi. Türk Psikolojik Danışma ve Rehberlik Dergisi, 4(39), 82-94. 16.3.2016 tarihinde erişilmiştir.http://dergipark.ulakbim.gov.tr/tpdrd/article/view/1058000157/1058000159.

Hoferichter, F. ve Raufelder, D. (2015). Examining the role of social relationships in the association between neuroticism and test anxiety-results from a study with German secondary school students. Educational Psychology, 35(7), 851-868. doi.org/10.1080/01443410.2013.849326.

Hoferichter, F., Raufelder, D., \& Eid, M. (2014). The mediating role of socio-motivational relationships in the interplay of perceived stress, neuroticism, and test anxiety among adolescent students. Psychology in the Schools, 51(7), 736-752.

Hu, L. ve Bentler, P. M. (1999). Cut off criteria for fit indexes in covariance structure analysis: Conventional criteria versus new alternatives. Structural Equation Modeling, 6, 1-55. https://doi.org/10.1080/10705519909540118.

Kagıtçıbaşı, Ç. (1996). The autonomous-relational self. European Psychologist, 1(3), 180-186.

Kagıtçıbaşı, Ç. (2005). Autonomy and relatedness in cultural context: Implications for self and family. Journal of Cross-Cultural Psychology, 36, 403-422.

Kapıkıran, Ş. (2012). Validity and reliability of the Academic Resilience Scale in Turkish high school. 
Education, 132, 474-483. http://eds.b.ebscohost.com/eds/pdfviewer/pdfviewer?vid=1\&sid= abb98a77-071c -4ad1-b80d-5cb7458d890c\%40sessionmgr102.

Kapıkıran, Ş. (2016). Ebeveyn akademik başarı baskısı ve desteği ölçeğinin psikometrik değerlendirmeleri ve yapısal geçerlik: Ortaokul ve lise öğrencileri. Ege Eğitim Dergisi, 17(1), 62-83. http://dergipark.ulakbim.gov.tr/egeefd/article/view/5000163356.

Kennedy, A. C. ve Bennett, L. (2006). Urban adolescent mothers exposed to community, family, and partner violence: Is cumulative violence exposure a barrier to school performance and participation? Journal of Interpersonal Violence, 21, 750-773. doi: 10.1177/0886260506287314.

Ketsetzis, M., Ryan, B. A. ve Adams, G. R. (1998). Family processes, parent-child interactions, and child characteristics influencing school-based social adjustment. Journal of Marriage and Family, 60, 374-387. doi: 10.2307/353855.

Koutsoulis, M. K. ve Campbell, J. R. (2001). Family processes affect students' motivation, and science and math achievement in Cypriot high schools. Structural Equation Modeling, 8, 108-127. doi: 10.1207/S15328007SEM0801_6.

Leung, G. S., Yeung, K. C. ve Wong, D. F. (2010). Academic stressors and anxiety in children: The role of paternal support. Journal of child and family studies, 19, 90-100. doi:10.1007/s10826-0099288-4.

Levpuscek, M. P., Zupancic, M. ve Socan, G. (2013). Predicting achievement in mathematics in adolescent students: The role of individual and social factors. The Journal of Early Adolescence, 33(4), 523-551. doi: 10.1177/0272431612450949.

Levpuscek, M. P. ve Zupancic, M. (2008). Math achievement in early adolescence: The role of parental involvement, teachers' behavior, and students' motivational beliefs about math. The Journal of Early Adolescence. 29(4), 541-570.doi:10.1177/0272431608324189.

Luthar, S. S. ve Becker, B. E. (2002). Privileged but pressured? A study of affluent youth. Child development, 73(5), 1593-1610. doi: 10.1111/1467-8624.00492.

Malecki, C. K. ve Demaray., M. K. (2006). Social support as a buffer in the relationship between socioeconomic status and academic performance. School Psychology Quarterly, 21(4). 375-395. doi: $10.1037 / \mathrm{h} 0084129$.

Martin, A. J. (2002). Motivation and academic resilience: Developing a model for student enhancement. Australian Journal of Education, 46, 34-49. doi:10.1177/000494410204600104.

Martin, A. J. (2013). Academic buoyancy and academic resilience: Exploring 'everyday' and 'classic' resilience in the face of academic adversity. School Psychology International, 34, 488-500. doi: $10.1177 / 014303431247275$.

Martin, A. J. ve Marsh, H. W. (2006). Academic resilience and its psychological and educational correlates: A construct validity approach. Psychology in the Schools, 43, 267-281. doi: $10.1002 /$ pits.20149.

Martin, A. J. ve Marsh, H. W. (2009). Academic resilience and academic buoyancy: Multidimensional and hierarchical conceptual framing of causes, correlates and cognate constructs. Oxford Review of Education, 35, 353-370. doi: 10.1080/03054980902934639.

McDonald, A. S. (2001). The prevalence and effects of test anxiety in school children. Educational Psychology, 21, 89-101. doi: 10.1080/01443410020019867.

McTigue, E. M., Washburn, E. K. ve Liew, J. (2009). Academic resilience and reading: Building successful readers. The Reading Teacher, 62(5), 422-432. DOI:10.1598/RT.62.5.5.

ÖSYM (2017). Sayısal Bilgiler.http://dokuman.osym.gov.tr/pdfdokuman/2017/OSYS/YER/ 15082017.pdf.

Perrone, K. M., Sedlacek, W. E. ve Alexander, C. M. (2001). Gender and ethnic differences in career goal attainment. The Career Development Quarterly, 50(2), 168-178. doi: 10.1002/j.2161-0045. 2001.tb00981.x

Pintrich, P. R., Smith, D. A., García, T. ve McKeachie, W. J. (1993). Reliability and predictive validity of 
the Motivated Strategies for Learning Questionnaire (MSLQ). Educational and Psychological Measurement, 53(3), 801-813. doi: 10.1177/0013164493053003024.

Putwain, D. W., Woods, K. A. ve Symes, W. (2010). Personal and situational predictors of test anxiety of students in post-compulsory education. British Journal of Educational Psychology, 80(1), 137-160. doi: 10.1348/000709909X466082.

Putwain, D. W., Nicholson, L. J., Connors, L. ve Woods, K. (2013). Resilient children are less test anxious and perform better in tests at the end of primary schooling. Learning and Individual Differences, 28, 41-46. doi:10.1016/j.lindif.2013.09.010.

Raufelder, D., Hoferichter, F., Ringeisen, T., Regner, N. ve Jacke, C. (2015). The perceived role of parental support and pressure in the interplay of test anxiety and school engagement among adolescents: Evidence for gender-specific relations. Journal of Child and Family studies, 24(12), 3742-3756. doi 10.1007/s10826-015-0182-y.

Richman, J. M., Rosenfeld, L. B. ve Bowen, G. L. (1998). Social support for adolescents at risk of school failure. Social Work, 43(4), 309-323. doi: 10.1093/sw/43.4.309.

Riley, P. J. (2003). The relationship between parental warmth and parental pressure to achieve adolescent depression and anxiety in china. (Unpublished master dissertation) Maryland: Faculty of the Graduate School of the University of Maryland at College Park). http://hdl.handle.net/1903/301.

Ringeisen, T. ve Raufelder, D. (2015). The interplay of parental support, parental pressure and test anxiety-gender differences in adolescents. Journal of Adolescence, 45, 67-79. doi.org/10.1016/j.

Rouse, K. A. G. (2001). Resilient students' goals and motivation. Journal of Adolescence, 24(4), 461-472. doi:10.1006/jado.2001.0383.

Sobel, M. E. (1982). Asymptotic confidence intervals for indirect effects in structural equation models. Sociological Methodology, 13, 290-312.. http://www.jstor.org/stable/270723.

Şahin, H., Günay, T. ve Batı, H. (2006). İzmir ili Bornova ilçesi lise son sınıf öğrencilerinde üniversiteye giriş sınavı kaygısı. Sürekli Tıp Ĕ̌itimi Dergisi, 15(6), 107-113.

Thomas, C. L., Cassady, J. C., \& Heller, M. L. (2017). The influence of emotional intelligence, cognitive test anxiety, and coping strategies on undergraduate academic performance. Learning and Individual Differences, 55, 40-48. doi.org/10.1016/j.lindif.2017.03.001.

Tüik, (Mart 2017). http://www.tuik.gov.tr/PreHaberBultenleri.do?id=27694. Bu veriye, 16 Temmuz 2018 yılında erişilmiştir

Turner, B. G., Beidel, D. C., Hughes, S. ve Turner, M. W. (1993). Test anxiety in African American School children. School Psychology Quarterly, 8, 140-152. doi:10.1016/0887-6185(94)90014-0.

Xiao, J. (2013). Academic stress, test anxiety, and performance in a Chinese high school sample: The moderating effects of coping strategies and perceived social support. Dissertation, Georgia State University. http://scholarworks.gsu.edu/cps_diss/88.

Verkuyten, M., Thijs, J. ve Canatan, K. (2001). Achievement motivation and academic performance among Turkish early and young adolescents in the Netherlands. Genetic, Social, and General Psychology Monographs, 127(4), 378-408. 18. 11. 2016 tarihinde erişilmiştir. http://www.jstor.org/stable/41064505.

Wang, M. T., ve Eccles, J. S. (2012). Social support matters: Longitudinal effects of social support on three dimensions of school engagement from middle to high school. Child Development, 83(3), 877-895. doi: 10.1111/j.1467-8624.2012.01745.x.

Wasonga, T., Christman D. E. ve Kilmer, L. (2003). Ethnicity, gender and age: predicting resilience and academic achievement among urban high school students. American Secondary Education, 32, 62-74. 18.11.2016 tarihinde ulaş1lmıştır. http://www.jstor.org/stable/41064505.

Yıldırım, İ. (2000). Akademik başarının yordayıcısı olarak yalnızlık, sınav kaygısı ve sosyal destek. Hacettepe University Journal of Education, 18, 167-176. http://dergipark.gov.tr/ download/article-file/88017. 


\section{Extended Abstract}

\section{Introduction}

It is one of the most challenging high school students in Turkey period. Most high school students have to continue their higher education or prepare for a challenging examination for a department they want. However, very few of the students can enroll in a department. Parents are able to put pressure on their children with the idea that their children need to work harder to achieve their own expectations. These pressures can often lead to exam anxiety.

Exam anxiety is a serious problem in decreasing the success of students. There are many reasons for exam anxiety. One of the important reasons is that parents have unrealistic expectations of success from their children.

Some parents behave in a way that promotes the success of their children, while others are supportive. The pressure of parents' success does not only affect the success of their children, but can also affect the emotional and social development of children. Parents may provide their children with behavioral support to provide learning materials, to provide information support and to facilitate their learning (such as private teaching). Parents' support for their children may increase their school success and learning orientations. On the contrary, children of parents who have a non-realistic expectation from their children can perceive this expectation as a pressure to succeed. However, some students may be academically resilient despite all the difficulties they face.

It is not enough for students to have only their potential and energy to achieve academic success. Students with high academic resilience are strong in overcoming the difficulties they face in their academic fields.

Parental success pressure is one of the factors that increase the anxiety of exam. Students who are subject to success pressure by their parents may increase their test anxiety. However, parents of children with supportive behaviors may be more successful. Moreover, supportive parents may be less concerned about the test.

Determining the nature of this relationship can lead to useful conclusions for psychological counseling and field literature research. School counselors can intervene more strongly on these issues if they have direct and indirect roles between academic resilience parents' support for pressure support and test anxiety.

\section{Method}

The data of the study were collected in three high schools in the city center. Data were collected from a total of 390 students, 223 (57.2\%) girls and 167 (42.8\%) boys. In the study, Academic resilience scale, test anxiety scale, Parent achievement pressure and support scale were used.

\section{Results}

In this study, academic resilience were tested whether or not is functioning as mediator between test anxiety and parent academic success pressure and support. The study consists of a model consisting of 26 observed and 4 latent variables (EABB, EABD, AD, SK). For the analysis, it was carried out in two stages as measurement and structural.

A three-step path was followed to test the structural model. The predictive variable parental academic achievement pressure and the index of direct relationship between parental academic achievement support and test anxiety ranged from acceptable to good fit values. 
In the second stage, the partial mediation model was tested. In the analysis at this stage, independent variables, dependent variables and all mediator variables were included. In this model, there is a negative $(-.14, \mathrm{P}=.05)$ between EABB and AD, positive between EABD and $\mathrm{AD}(.23, \mathrm{P}<.01)$ and negative $(-.36, \mathrm{P}<.01)$ direction between $\mathrm{AD}$ and SK. significant relationship was found (Table, 3 )

In the third stage, the fully mediated model was tested. At this stage, it is tested whether the mediator variable (academic resilience) is the mediator between the independent variable (parental academic achievement pressure and parental academic success support) and dependent variable (exam anxiety). The relationship between $\mathrm{EABB}$ and $\mathrm{AD}(\beta=-.14, \mathrm{P}<.05)$, between EABB and SK $(.21, \mathrm{P}<.01)$, between EABD and $\mathrm{AD}(\beta=.23, \mathrm{P}<.01)$ The relationships between EABD and SC ( $\beta=$.-. 13, P <.05) were obtained (Fig. 4). In other words, academic endurance has full mediation between EABD and SK $[\beta=-.13, \mathrm{P}<.05)(\beta=-.03, \mathrm{P}>.05)]$ (Figure 4).

As a result, it has been found that academic resilience is a complete mediation between parental academic achievement support and test anxiety. However, the mediating role of academic resilience between parental academic achievement pressure and test anxiety remained partial.

\section{Discussion}

As a result of the analysis of the data obtained, it has been shown that parents' academic success pressure has a positive role on test anxiety. In other words, the parental achievement pressure increases the anxiety of the exam. Based on the literature and this finding of the current research, it may increase the anxiety of children's examination when parents force their children to achieve their own achievement standards. Parents should not put pressure on their children to succeed. Another finding obtained in our study is to determine a negative relationship between parental achievement support and test anxiety. When parents support their child to succeed, the feeling of test anxiety may be reduced. Another finding related to the direct relationship in the research is that there is a negative correlation between the achievement of parents and pressure of academic achievement. The pressure of success of adolescents by their parents can also cause serious psychological problems. However, in our study, it was found that the support of the parent achievement has a positive role on the academic resilience of the students. According to this result, parents should be supported in order to strengthen the academic resilience of students who are under stress and failure pressure during their studies. There is a negative relationship between academic endurance and test anxiety. In other words, as the academic endurance increases, the test anxiety of the individual decreases.

Nevertheless, academic resilience has full mediation between parental academic achievement support and test anxiety. According to this result, students with high academic resilience have higher levels of anxiety on the exam of students with high academic achievement support. Emotional and behavioral support should be offered to overcome these difficulties especially when faced with difficulties. 